\title{
Getting Healthy Without Getting High: Lexaria's Approach to Cannabinoids
}

\author{
Sylvain Charlebois \\ Faculty of Management, Dalhousie University, Canada \\ E-mail: Sylvain.Charlebois@dal.ca
}

Received: March 18, 2018 Accepted: July 20, 2018 Published: July 23, 2018

doi:10.5296/jfs.v7i1.13414 URL: https://doi.org/10.5296/jfs.v7i1.13414

\begin{abstract}
The legalization of cannabis in Canada has been a controversial issue. Over the last few years most of the attention has been on the production and distribution of cannabis. As the public discourse on cannabis matured, the drug and inherent benefits remained misunderstood by industry, policymakers, and consumers alike. Lexaria Bioscience, a British Columbia-based licensing company in Canada, is attempting to change how we market edibles in Canada and elsewhere. This case study first looks at the market of cannabis in general. It then describes how the company began to investigate cannabinoids. Based on interviews conducted with key informants in the company, some key elements of Lexaria's business model were isolated, including their challenges. The company argues that many people want to consume edibles without the psychoactive effects of THC. This case study attempts to conceptualize what the state of the market should look like to accommodate Lexaria's technologies and the commercialization of edibles. A discussion on the case is presented and future research paths on edible research are suggested.
\end{abstract}

Keywords: cannabis, edibles, public health and safety, innovation

\section{Introduction}

Canada will become one of the first countries to fully legalize cannabis consumption on a national level (Rehm, Crépault, \& Fisher, 2016), and the first of the G7 countries to do so. Most of the discussion surrounding the legalization of cannabis in Canada has been focused on production challenges and distribution policies within provinces. Edibles did not become part of the collective conversation until November 2017. Edible cannabis products are food items made with cannabis or cannabis oils that can be used as an alternative to smoking or vaporizing the drug. As part of an amendment accepted by the House of Commons' Health Committee, edibles became included as part of the discussion around the legalization of cannabis (Canadian Press, November 2017; Vogel, 2017). 


\section{Macrothink}

Many consumers associate the consumption of cannabis with its psychoactive effects and the harm these effects represent towards children and adolescences (Spackman et al., 2016). Few understand and appreciate how the legalization of edibles can influence our relationship with the drug, including policymakers and industry (Charlebois, Somogyi, \& Sterling, 2018). Very little attention has been given to how to extract the benefits of cannabis as a food ingredient. Given that the drug was prohibited in Canada for decades, the stigma remains and influences policymaking and commercialization of the product.

Lexaria Bioscience (Lexaria), a British Columbia-based company in Canada, has developed a new disruptive drug delivery platform, called DehyraTECH ${ }^{\mathrm{TM}}$. The technology changes how active pharmaceutical ingredients enter the body orally. It is designed to mask unwanted tastes, reduce time of onset through avoidance of liver metabolic pathways, and increase bio-absorption of nutrients. Lexaria believes its technology can revolutionize how we market cannabinoids (Health \& Beauty Close - Up, April 2017).

The aim of this case study is to look at how Lexaria can alter the evolution of the edible market in Canada and beyond in the years to come. Legalizing cannabis in Canada offers a unique market environment, which few can predict its progress. We first look at the current state of the cannabis market in Canada, followed by a description of Lexaria. A conceptual framework which looks at enabling, desirable market conditions which can allow one agent, or a company to extract benefits of a commodity, allowing it to serve heterogeneous markets. Finally, findings of the survey are discussed, and future research paths are considered.

\section{Cannabis Market}

Since 1999, Canada has provided access to cannabis for medicinal purposes. Unlike many U.S. states that have medical cannabis systems, Canada limited distribution to a mail order system by licensed producers (Bear, 2017). One estimate suggests that Canadians will consume about 700 metric tons of marijuana flower for medicinal purposes in 2018, and that number could reach about 861 metric tons by 2022 (Olive, 2018). Most people who consume cannabis are low-salary earners (Werb et al., 2012). Some high-earning consumers may try cannabis once it is legalized but few expect to consume the product every day. Many Canadians anticipate trying edibles, once legalized, but it is unclear whether consumers will purchase edibles regularly or consume the drug in a restaurant (Charlebois, Somogyi and Sterling, 2018). Once legalized, some expect the cannabis market to exceed current national beer sales, which is around $\$ 10 b$ ((Rehm, Crépault and Fisher, 2016) (Note 1).

Uruguay was the first country to legalize non-medicinal cannabis, and more countries are expected to follow suit. Currently, almost 600 million consumers around the world live in a region where cannabis is legal, and Lexaria expects that number to increase in years to come. The social agenda and with more governments needing to increase revenues will drive more countries to consider legalizing cannabis.

It is estimated that many people consume medical cannabis for recreational purposes, especially in the United States. Lines are blurred between both purposes, mainly because recreational usage is for the most part illegal. Medicinal cannabis is legal in thirty (30) states in the U.S. Non-medicinal use is now legal in nine states: California, Massachusetts, Maine, Nevada, Colorado, Alaska, Washington and Oregon (Mold, 2017). It is unknown how the 


\section{MInstitute ${ }^{\text {Mink }}$}

Canadian market will evolve in years to come.

At PubMed a search for cannabis returns 17,682 references; a search for tetrahydrocannabinol returns 8,349 references; and a search for cannabidiol generates 1,934 references. Understanding the characteristics of individual active ingredients within cannabis is at a very early stage and understanding the relationships between those active ingredients within cannabis is even less well understood. Likewise, while the data on inhaled cannabis is robust, data collection on its edible forms is in its infancy. We know little about the effects of edibles which influence regulators ability to evaluate risks before adopting any laws.

\section{Methodology}

We chose an exploratory case study design to guide our investigation based on Yin's (1994) argument that case studies are the preferred strategy when 'how' or 'why' questions are being posed and when the focus is on a modern phenomenon within a real-life context. In our study research data was collected through multiple approaches. A semi-structured questionnaire was designed and adopted to collect primary data. The objective of the empirical segment is not to test the applicability of the existing approaches, but rather to study conceptual nuances related to the presented model.

A survey study focused on formal interviews with executives from Lexaria in Toronto, in February 2018. Comments were recorded comprehensively for supporting analysis. Respondents were interviewed as key informants in a variety of functional areas, including the Chairperson and President of Lexaria. These individuals possessed sufficient experience and understanding of the organization's culture and strategic intents to be able to comment with authority on the history of Lexaria and knowledge on the cannabis market. The interview questions were largely designed to be open-ended to provide flexibility in interview discussions. The interviews provided information on the perceptions, application, and experience of strategy in licensing. The collected data was arranged, analyzed and put into the subsequent application phase. A draft version of the paper was submitted for review to the organization for internal validity (Yin, 1994). This case study proposes to uncover best practices in expanding markets in cannabis use in Canada, and elsewhere.

\section{Lexaria Bioscience Corp}

Lexaria Bioscience Corp. is essentially a licensing company based in Kelowna, British Columbia, but the company is incorporated in Nevada. The company does not grow plants or manufacture any THC or cannabis products. Lexaria is a publicly traded company, listed as CSE:LXX/OTCQB:LXRP. Lexaria's market capitalization is at around $\$ 100 \mathrm{~m}$. The company was originally an oil and gas company. It originated in its current form in 2014 upon controlling acquisition of the former company Lexaria's DehyraTECHTM Lexaria only has a handful of employees but manages several partnerships with research centers. Chris Bunka is the Chairperson and CEO of the company and has been involved with Lexaria since 2006. He is the business mind behind Lexaria. John Docherty is President and Director and manages the portfolio of patents and R\&D development. He joined Lexaria in 2015. He is the former President of Helix BioPharma in Toronto. Allan Spissinger is Lexaria's Chief Financial Officer and joined the group in 2014. Alex Blanchard is responsible for the firm's communications. 


\section{Macrothink}

"In August 2014, we had a "come to Jesus" moment as a company." Chris Bunka, Chairperson, Lexaria

When regulations around cannabis began to be discussed and shifted, knowing that Fortune 500 companies are not allowed to enter the market, Lexaria saw it as an opportunity. From May 2014 to September 2014 was an evolutionary period for the company. While seeking a license under Canada's MMPR program, Lexaria took an ethical stance and publicly decided not to sell cannabis products to consumers under the age of 25, if a license is granted to the company (Elrod, 2017). This stance came as a surprise for the industry, and many reacted negatively to the news. Market reactions at the time were swift. Several companies considered Lexaria's position as problematic for the industry given that almost half the market would likely be under the age of 25 (Charlebois \& Watson, 2008; Charlebois, Sterne, \& Buhr, 2015).

Lexaria rapidly emerged as a player in enhancing the flavour, bouquet, and gastro-intestinal delivery of edible cannabinoid consumer products. It is simultaneously working to expand the applicability of its technology, within and beyond the cannabinoid sector, through its out-licensing business model for cannabinoids and other bioactive molecules named in its patent portfolio (NSAIDs, nicotine, vitamins and more) (Lexaria, 2018).

In regard to edibles, market development at Lexaria is essentially with food product manufacturers for white labelling. Lexaria now receives as many incoming requests as the company initiates outgoing sales prospects. Lexaria always attempts to engage with ultimate decision makers. The company often meets with companies experiencing flavour issues in the delivery of edible forms of cannabis. Absorption is another challenge. US states such as California, Colorado and Nevada have effectively adopted legislation that limits the THC content of cannabis edibles to not more than $10 \mathrm{mg}$ per serving. Companies that can no longer input over 10 milligrams of THC in a food product due to new regulations are looking for solutions (Bibi, 2010). Given that the digestive track only absorbs $6 \%$ of the cannabinoids, 10 milligrams within a product is too little an amount and therefore companies are looking for methods to enhance the effects. The speed of absorption is also a challenge. Compared with inhalation, it takes longer for a person to feel the effects when ingesting cannabis, whereas DehyraTECH ${ }^{\mathrm{TM}}$ formulations have demonstrated onset of THC and CBD effectiveness within 20 minutes.

New clients tend to pilot a product with Lexaria and evaluate any number of formulations. Sensory studies are conducted to assess how the market reacts to the new products. It can take a few months to process from a non-disclosure agreement (NDA) to a letter of intent (LOI). It can take even longer, from a LOI to a definitive commitment. The sales cycle can be lengthy. Sensory investigations can be used by Lexaria to close contracts with other companies.

Applications for the technology are very broad. For example, Lexaria is doing business with a well-known Montreal-based chocolatier. Lexaria has also formulated non-alcoholic beer with cannabis and has additionally worked on tea, coffee, hot chocolate, chocolates, protein bars, candies, gummy bears, fruit juices and more. For beverages, mixing water with cannabis oil is difficult but achievable with the company's technology, but the intent is to make beer taste like beer rather than the strong taste of terpenes and other overwhelming flavours of cannabis 


\section{$\triangle$ Macrothink}

constituents which are objectionable to the average new cannabis product consumer.

\section{Lexaria and "Patentocracy"}

As a license provider, it was important for Lexaria to strengthen its patent portfolio. According to Lexaria, there are two key components to patenting: Method of use and composition (or ingredients). At the time of the case study, Lexaria has 19 applications filed in the U.S., and 33 globally, in over 40 countries. Lexaria files first in the U.S., before filing a Patent Corporation Treaty (PCT) application, which allows the company to file in countries that are PCT subscribers. The company files when the product is ready in specified markets. Lexaria has 2 issued patents in the U.S., and one in Australia (Labrecque, Dufour, \& Charlebois, 2015; Health \& Beauty Close - Up, 2017). Lexaria's issued patents are focused on methods of use with composition claims pending.

Lexaria is a first mover and is aggressively seeking patents before the much larger multinationals capture some of the markets. Lexaria's IP is centered around the delivery of active ingredients and drugs rather than the applications for those ingredients or drugs. Lexaria's technology is equally applicable for use by a Fortune-500 drug company with its own patented drug as it is for a consumer product in the food category. Lexaria recognized that they are delivering a new delivery platform and are dissimilar to Canopy or Pfizer, more well-known companies. Lexaria believes it is holding one of the broadest portfolios of patents related to cannabinoid research.

"We have ears, so we can hear, mouths so we can drink and eat. Lungs are to breathe. Lungs are not meant to deliver drugs. That is not what nature intended." Chris Bunka, Chairperson, Lexaria.

Patents protect the use of technologies and their various applications. New liposomal technologies and their patent applications largely peaked in 2007. Patents last about 20 years, and Lexaria's DehyraTECH ${ }^{\mathrm{TM}}$ represents the start of the next generation of lipid-based delivery technologies. Liposome technology works by utilizing liposomal micro spheres to enhance gastrointestinal bioabsorption. Lexaria's DehydraTECH ${ }^{\mathrm{TM}}$ brings forth a new approach to achieve this that is both cost effective and consumer friendly. DehydraTECH formulations are designed to lever physiological mechanisms for the intestinal absorption of certain fatty acids that are combined with the bioactive molecule at a molecular level through Lexaria's patented dehydration synthesis process. In addition, DehydraTECH ${ }^{\mathrm{TM}}$ formulations are believed to provide nutrients with protection during passage through the destructive track of the digestive system and they are also believed to avoid first-pass liver metabolism and instead use the lymphatic circulatory system for active ingredient delivery. Bypassing the liver allows more nutrients into the bloodstream, and to do so more quickly. Lexaria's patented technology, therefore, reduces time of onset, which means effects can be felt within 20 minutes in lieu of 90 to 120 minutes (Krauss et al., 2017), while also allowing edibles to be effectively dosed at very low, so called micro-dose levels. Lexaria's patents can even offer products that are certified Kosher, organics, gluten-free and more.

"Of course, we want to make money, but if anything, we want people to stop smoking pot." Chris Bunka, Chairperson, Lexaria.

The market has shifted in recent years. In August 2017, for the first time in Canadian history, 


\section{MInstitute Macrothink $_{\text {Int }}$}

more cannabis was sold in an oil form than in a smokable form. The challenge with oil-based products with cannabinoids is the bitter taste through ingestion. Manufacturers tend to avoid bitterness by using more sugar and sweeteners. In fact, the best-selling edible in the United States are gummies (Sobesky \& Gorbens, 2016). As a result, the health value of the food product is compromised. For consumers who are diabetic, as an example, this can be an issue (Labrecque, Dulude, \& Charlebois, 2015). Many benefits of cannabinoids come from the non-psychoactive parts of the plant. Edible forms of cannabis product allow modern companies to remove undesirable elements or ingredients within the cannabis before creation of the edible. THC is not necessary and can be extracted and removed/reduced, and terpenes and NON-psychoactive cannabinoids can be concentrated for edible products. The company believes that most consumers do not want to smoke cannabis just as they do not want to smoke cigarettes: edible forms are much healthier.

\section{Regulatory Framework}

With its bioscientific approach and licences, Lexaria estimates that the global market potential for its technology with cannabinoids is $\$ 8$ billion USD. For other applications like vitamins, nonsteroidal anti-inflammatory drugs and even nicotine, the estimated market potential is over $\$ 700$ billion USD. Creating a buffer between the plant and consumer goods is where Lexaria believes the bulk of the market is.

According to Lexaria, the regulatory regime around cannabis in Canada and elsewhere is problematic. Lexaria believes regulators and public officials do not understand the diversity of cannabinoids. In the case of edibles, the lack of understanding is even more acute. The whole notion of edibles challenges Health Canada. Lexaria believes in regulations, but they need to be thoughtful and comprehensive. Lexaria believes that the larger market for cannabis is not overly interested in the overt psychoactive intoxicant effects offered by the drug. Regulations ought to aim at regular consumers wanting to relax similar to the typical social beer or wine drinker. Ideally, companies should maximise the efficiency and reliable predictability of delivery of cannabinoids.

Once edibles become legal, many larger players will enter the market which will make the market more competitive. With its patent applications, Lexaria hopes to be at the forefront of the game and is trying to be the gatekeeper in edibles. In the U.S., the regulatory environment is very different. There is a lot of fear in United States around cannabis. Since 2017, it seems worse. Banks, insurance companies are very careful with cannabis. The perception of money laundering linked to cannabis is still widespread in the U.S. which in turn affects how regulators manage risks (Charlebois, Von Massow, \& Pinto, 2015).

\section{Conceptual Framework}

The agrifood system is a symbiotic set of institutions, firms and markets contributing to the production, processing, and distribution of agricultural products to satisfy nutritional needs of people (Caiazza, Volpe, \& Audretsch, 2014). Ingredients facilitate connections amongst firms for their betterment and to enhance the efficiency of the system (Charlebois \& Mackay, 2010).

The food industry is in a constant quest to find new ingredients which enables innovation (Fitzpatrick, 2007). The emergence of the retail cannabis legalized economy has led to 


\section{Macrothink}

numerous new products, including products less commonly used before legalization, such as edibles (Allen et al., 2017). But given that cannabis has a long history of cultural and social stigma, and perhaps even misinformation (Maccoun \& Mello, 2015), several remain legitimately concerned about its physiological influence on youth (Friese, Slater and Battle, 2017; Richards, Smith, and Moulin, 2017). Regulators are starting to explore ways in which lessons from tobacco and alcohol can be applied to cannabis to reduce unintended negative consequences of legalization. Jurisdictions that have legalized marijuana for recreational use, including a few American states, are eager to develop and adapt product, packaging and labelling standards designed to prevent unexpected negative externalities. Currently though, limited research is available to guide the development of policy frameworks (Wang et al., 2016).

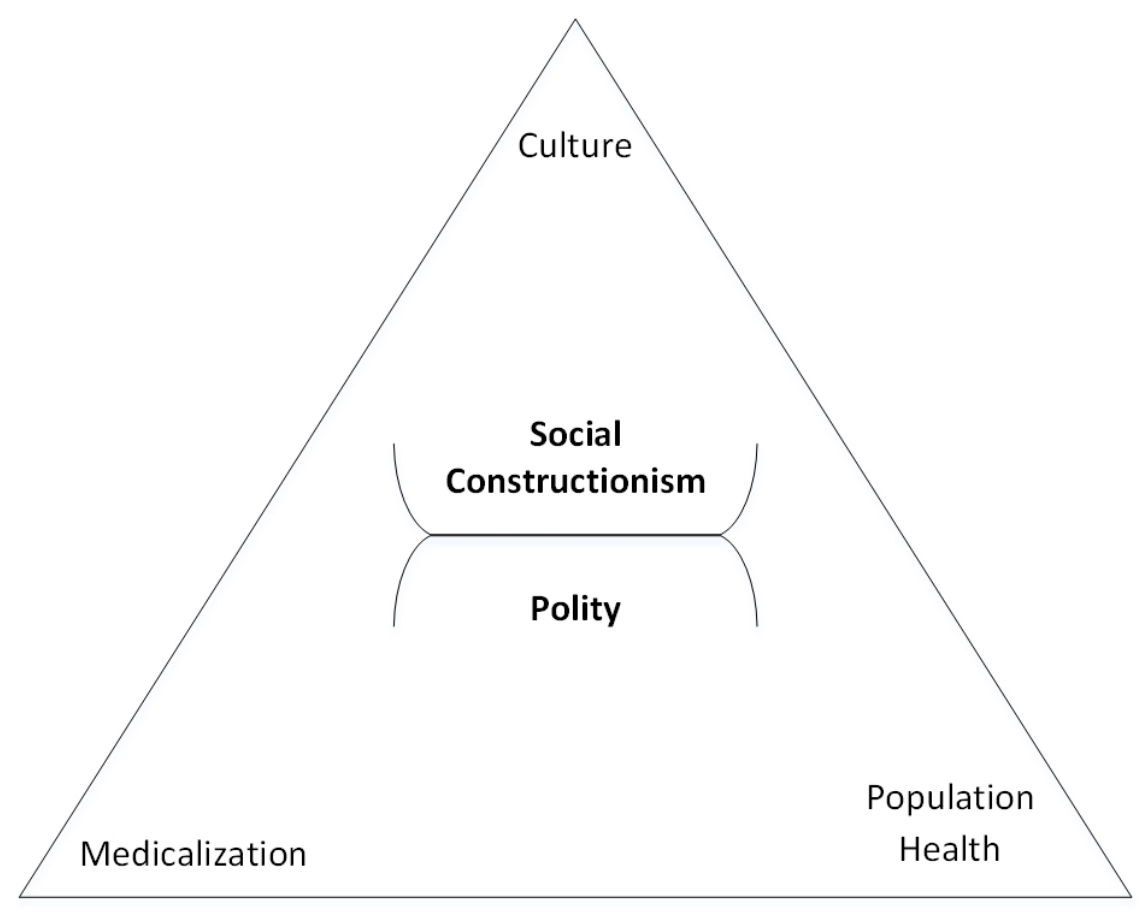

Figure 1. Dimensions to a balanced between polity and social constructionism for edibles

The use of cannabis and the commercialization of cannabis-infused food products is inextricably linked with the key components of human societies: culture, polity, economy, law and order, and other aspects of social life (Chapkis, 2007; Charlebois, Creedy, \& von Massow, 2015; Szaflarski \& Sirven, 2017). On the one hand, polity represents rules, regulations and institutions which provides rule of law for everyone. It is how a society channels power which allows it to be organized in particular ways. The role of policy-makers in agrifood innovations includes managing uncertainty, providing information, and facilitating networks (Nasser et al., 2011). The food industry follows specific regulations while being influenced by market forces. In addition, social constructionism is a market-based phenomenon. Stigma in a sense, is an outcome of social constructionism. Social constructionism is a theoretical perspective based on the idea that scientific knowledge and biological discourse about our health, including illnesses, are generated by subjective, 


\section{$\underline{\Lambda \text { Macrothink }}$}

biases, which changes over time due to the evolution of our collective knowledge on a social issue (Balazic, Wilcock, Hill, \& Charlebois, 2013; Malek, 2017). Cannabis has been an illicit drug for decades in Canada. Over the years, the drug itself has been culturally perceived in certain ways (Keul, 2018).

Culture is a critical dimension to the commercialization of edibles. Culture is essentially our way of life, which includes values, beliefs, customs, languages, and traditions. Culture is reflected in our history, in our heritage and in how we express ideas and creativity. Some may see the existence of edibles as a natural extension of our culture while others will not (Le Vallée \& Charlebois, 2015).

Cannabis has also been associated with medicine for years, which can lead to the medicalization of an ingredient. Medicalization, another key dimension, is the process by which previously nonmedical problems become defined and treated as medical problems (Cathcart et al., 2016). Several ingredients have been promoted as superfoods, to resolve certain ailments (Lamy et al., 2016). The treatment itself is then associated with the medical problem. Social acceptance fostered by celebrity endorsement, as an example, can alter how an ingredient is perceived. In the case of cannabis, the association between health and benefits has been building slowly over the years which could have categorized cannabis as a medication, and not a general food ingredient (Vo et al., 2018). As a result, to broaden the market of edibles can be challenging.

Population health is another dimension to a broader analysis of cannabis as an ingredient. Social determinants of health can also affect perceptions of an ingredient. The social determinants of health (SDH) are social characteristics of individuals and conditions in which individuals live and work (e.g., housing, and occupational environment) that determine their health status. The pursuit of better health does generate more innovation within the food industry (Giombi et al., 2017). A blend of all dimensions can strike a balance between polity and social constructionism (see Figure 1). Some long-term clarity can be provided in public policy and how markets can be developed for ingredients that were illegal for decades.

\section{Findings}

Lexaria's goal over the next five (5) years is to become a company with a valuation of over one billion dollars. Lexaria sees itself as a game-changing agent, a broker of knowledge between manufacturers and the market. With cannabis, it sees itself as the enabler for manufacturers wanting to grow the cannabis-infused market. The quality of edibles has been mediocre for several reasons. The bitter taste of cannabis had to be hidden by using sugary ingredients that are not healthful but traditionally a "sole solution", as evidenced by strong demand for cannabis in candy. Cannabis edibles historically give unpredictable results due to variations in individual body chemistry and gastro-intestinal processing. Additionally, liver metabolism of cannabinoids subtly alters them to at times make them more psychoactive than inhaled versions of those same cannabinoids. And finally, consumers would often ingest a large quantity of cannabinoids via edibles due to often poor absorption. Lexaria's patented technology offers solutions to all three of these challenges that it believes are in accordance with consumer demand and expectations. Entering the cannabis market for Lexaria is seen as a natural progression for the company. 


\section{Macrothink}

"Going into cannabis was essentially a business decision for Lexaria." Chris Bunka, Chairperson, Lexaria.

The company appears to be strategic about its position. It also appears not to be cash-strapped (Lexaria, 2017). As well, Lexaria wants to change how cannabis is perceived and consumed. During our interview, Bunka articulated how Lexaria's is attempting to change the way cannabis is used and perceived in the Western world.

"You shouldn't get high to get healthy and relax. The soccer moms and hockey dads coming home wanting to relax, that's the fat of the market with edibles." Chris Bunka, Chairperson, Lexaria

Physicians and professionals are ill-prepared for what is happening in the edible market in Canada and abroad. Policies are unclear at best. In fact, Lexaria has expressed concerns about the lack of regulatory oversight or will from public regulators to look at this issue seriously.

"In the United States, the maximum dosage for an edible product is 10 milligrams. That is becoming the standard around the world. But in Canada, it is the wild West." Chris Bunka, Chairperson.

This is making Lexaria's work more challenging. As a small player in the industry, time is not something Lexaria has plenty of. They have minimal recourses to really make a mark in such a very large market. Innovation is critical to the growth of the food industry. The different types of innovations can affect numerous stages of the value chain that leads to the transformation of inputs into food products for human consumption and may vary depending on the relative power of actors in the system. In product-driven value chains, which are typically dominated by manufacturers, innovation pertains to know-how and is focused on products and processes. In buyer-driven value chains, which are dominated by food distributors, innovation is related to branding and marketing and is focused on organization and marketing activities. Lexaria is neither, which makes the company incredibly vulnerable to supply-chain forces.

Another issue which came up during interviews was where the company was listed-in the U.S. Being listed in the U.S. does expose the company to some risk. The American federal administration has mentioned that it could enforce new rules and restrictions related to cannabis consumption. It may even ban the existence of some companies like Lexaria which can be problematic over time. It could also affect the company's ability to attract capital in the future, which is critical for a company like Lexaria. In addition, Lexaria has several opportunities but has limited capacity. Investigating an avenue with no potential in the end can be fatal to the company. In other words, choosing the wrong venture can lead to bankruptcy. In response to this challenge, Lexaria has begun the legal process of redomiciling: dis-incorporating its head office from the USA and incorporating a new head office in Canada, where cannabis businesses are federally accepted.

\section{Discussion}

Lexaria has an intriguing business model with great potential. But it also has vulnerabilities which cannot be ignored. The company is putting forward a narrative which does not fit with the current dominant rhetoric around the consumption of cannabis (Charlebois, 2015). Lexaria aims at a balance between social constructionism and polity, but it is unclear when 


\section{$\triangle$ Macrothink}

such a balance will be attained. Such a state requires an entire system to converge. Based on current regulations and how cannabis is perceived, both society and science have not reached a point where all dimensions (medicalization, culture and public health) are open markets to edibles using Lexaria's technology.

Generally, in agrifood, major technological, political, economic, and institutional trends are changing the agrifood global system. But the case of legal cannabis is different, and social constructs will vary from one market to another. Main drivers of change usually involve information and communication technologies, biotechnology, agricultural research and development systems, globalization of agribusiness supply chains, the rapid growth of foreign direct investment and international trade. Cannabis can allow, or disallow, firms or markets to reach their full potentials.

In Canada, most of the attention on cannabis has been related to production challenges and distribution. The issue of ingredient enhancement has rarely been covered. The global market for cannabis-infused food products and nutritional supplements is expanding with the liberalization of cannabis laws and the discovery of new therapeutic applications of cannabinoids. Canada offers a fertile terrain of research on how consumers will adapt to such an environment. Companies are also attempting to make sense of a market in transition. A company like Lexaria attempts to clarify how a commodity can better connect with a demand affected by entrenched social contracts.

One early lesson has already been learned. Currently in Canada only two forms of cannabis are fully regulated for sale to the consumer: plant material (bud) or non-processed oil extracts. Old laws that prevented legal edibles have been struck down by the courts, but replacement legislation has not yet been introduced and is not expected before mid-2019. In August of 2017 on a monthly basis, for the first time in Canadian history, the Licensed Producers collectively sold more oil extract than they did bud material. This trend has continued every month since, for which data is currently available. Consumers seem to be expressing their demand for non-smokable cannabis choices and Lexaria believes this trend will continue as additional legislation is introduced allowing for broader edible formats.

Lexaria, as a company, is not really start-up as it has been around for several years. The cannabis market is also in a unique place. As an illicit drug, it has been in the market for quite some time, but the Canadian market is not over knowledgeable about the use and benefits of cannabinoids in general. Most do not understand the risks which in turn is affecting policy.

"We know despite the harm of smoking cannabis, Canadian physicians will gravitate towards inhaled products because most understand pharmaceutical kinetics. Edibles are misunderstood." John Docherty, President and Director, Lexaria

Most professionals do not know of other methods of delivery, which can impact how Lexaria markets its technologies. Lexaria is positioned between the production and consumption of cannabis and tries to connect in order to enhance the experience of both medicinal and non-medicinal cannabis use. The way Lexaria is positioning itself and how it sees the market differs from mainstream thinking.

"It has been our thesis for a while that Canopy's biggest competitor is not going to be Aphria. It's going to be Loblaw, or Campbell's." Chris Bunka, Chairperson, Lexaria 


\section{MInstitute ${ }^{\text {Mink }}$}

Copycats are inevitable. Smaller players could copy Lexaria's technology and compete. The larger players are more exposed and cannot do the same thing. However, Lexaria will need to secure many patents quickly in order to protect the intellectual property it needs to become successful, before major companies start competing in the same space. Access to capital will be key in moving forward. To become less vulnerable, some information was given on the fact that Lexaria is in the process of moving the company to Canada. The intent is to make the company less vulnerable to a potentially harsher regulatory regime in the U.S. Lexaria expects its valuation to increase with a move to Canada.

This case is very much about cannabis, but Lexaria is also working with nicotine. Unlike cannabis, nicotine can be fatal. There is no edible version of nicotine, but Lexaria believes it can change that due to its technology - already patented in the USA for nicotine delivery that it believes will allow the human GI to tolerate nicotine within it for the first time ever. Lexaria believes that global demand for a healthier alternative to smoking cigarettes is so strong as to give its technology an opportunity to present solutions via an entirely new type of consumer product: nicotine edibles. Lexaria's technology eliminates most of the negative health and disease aspects of what many consumers have inhaled for decades. So, the technology developed and marketed by Lexaria has many applications.

\section{Conclusion}

The findings from the empirical study have contributed to evolving the debate on cannabis and edibles. Our specific contribution depends on the mode of delivery of the drug and how it could change how cannabis infused food products can benefit consumers. We argue that polity and social constructionism may affect market development and policy. Lexaria is a unique company looking at a unique market. Even though Canada is not the most interesting market for Lexaria, it does consider the country as a unique opportunity to learn about how a market deals with the stigma related to a specific commodity.

Cannabis, as an ingredient, remains controversial and will remain so for a while. This case study is intended to broaden the public discourse on cannabis and perhaps induce many to see cannabis in a different light. More research is required to better understand social contructs over time while cannabis is being legalized. Canada, and perhaps other countries where cannabis will become legal, can offer a unique terrain for future social science research on the topic.

\section{References}

Allen, Davis, Duke, Nonnemaker, Bradfield, \& Farrelly. (2017). New product trial, use of edibles, and unexpected highs among marijuana and hashish users in Colorado. Drug and Alcohol Dependence, 176, 44-47. https://doi.org/10.1016/j.drugalcdep.2017.03.006

Balazic, S., Wilcock, A., Hill, A., \& Charlebois, S. (2013). Food safety performance: labeling and indications of allergens. Food Prot Trends, 33(4), 232-9.

Bear, D. (2017). From Toques to Tokes: Two challenges facing nationwide legalization of cannabis in Canada. International Journal of Drug Policy, 42, 97-101. https://doi.org/10.1016/j.drugpo.2017.03.002

Bibi, J. (2010). Using the Benchmark Dose (BMD) Methodology to Determine an Appropriate Reduction of Certain Ingredients in Food Products. Journal of Food Science, 
75(1), R9-R16. https://doi.org/10.1111/j.1750-3841.2009.01397.x

Caiazza, R., Volpe, T., \& Audretsch, D. (2014). Innovation in agro-food chain. Journal of Enterprising Communities, 8(3), 180-187. https://doi.org/10.1108/JEC-06-2014-0009

Cathcart, J., Aguirre, Adalberto, Kposowa, Augustine, \& Reese, Ellen. (2016). Knowledge of Good and Evil: An Urban Ethnography of a Smoking Culture. ProQuest Dissertations and Theses.

Chapkis, W. (2007). Cannabis, Consciousness, and Healing. Contemporary Justice Review, 10(4), 443-460. https://doi.org/10.1080/10282580701677550

Charlebois, S., \& Watson, L. (2008). Risk communication and public trust. The crisis of food brands: Sustaining safe, innovative and competitive food supply. Gower Publishing.

Charlebois, S., \& Mackay, G. (2010). Marketing culture through locally-grown products: The case of the fransaskoisie terroir products. Problems and Perspectives in Management, 8(4), 91-102.

Charlebois, S., Sterne, R. H., \& Buhr, M. (2014). Sharing and preparing: cross-institutional, food security-based knowledge in Canada. International Journal of Sustainable Development \& World Ecology, 21(6), 532-539. https://doi.org/10.1080/13504509.2014.971905

Charlebois, S., Von Massow, M., \& Pinto, W. (2015). Food recalls and risk perception: An exploratory case of the XL foods and the biggest food recall in canadian history. Journal of Food Products Marketing, 21(1), 27-43. https://doi.org/10.1080/10454446.2013.856055

Charlebois, S., Creedy, A., \& von Massow, M. (2015). "Back of house"-focused study on food waste in fine dining: the case of Delish restaurants. International Journal of Culture, Tourism and Hospitality Research, 9(3), 278-291. https://doi.org/10.1108/IJCTHR-12-2014-0100

Charlebois, S. (2015). In the end it's about respect. Nature Biotechnology, 33(5), 437-438.

Charlebois, Somogyi, \& Sterling. (2018). Marijuana-infused food and Canadian consumers' willingness to consider "recreational" marijuana as a food ingredient. Trends in Food Science \& Technology, 74(10). https://doi.org/10.1016/j.tifs.2018.02.009

Conrad, P. (1975). The discovery of hyperkinesis: notes on the medicalization of deviant behavior. Social Problems, 23(1), 12-21. https://doi.org/10.2307/799624

Elrod, M. (2017). Cannabis prohibition harms Canada's youth. CMAJ : Canadian Medical Association Journal = Journal De L'Association Medicale Canadienne, 189(29), E970.

Federal marijuana legislation approved by Commons, moves on to Senate. (2017, November 27). The Canadian Press.

Fitzpatrick, K. (2007). Innovation in western Canadian functional food ingredients. Cereal Foods World, 52(5), 289-290. https://doi.org/10.1094/CFW-52-5-0289

Friese, B., Slater, M., \& Battle, D. (2017). Use of Marijuana Edibles by Adolescents in California. The Journal of Primary Prevention, 38(3), 279-294. https://doi.org/10.1007/s10935-017-0474-7

Henderson-Ross, J., Feltey, Kathryn M., Lee, Matthew, Lyons, William, Taylor, Tiffany, Teasdale, Brent, \& Zipp, John. (2014). Informal Social Control in Action: Neighborhood Context, Social Differentiation, and Selective Efficacy. ProQuest Dissertations and Theses. 


\section{MInstitute Macrothink $_{\text {Int }}$}

Journal of Food Studies ISSN 2166-1073 2018, Vol. 7, No. 1

Giombi, K., Kosa, K., Rains, C., \& Cates, S. (2017). Consumers' Perceptions of Edible Marijuana Products for Recreational Use: Likes, Dislikes, and Reasons for Use. Substance Use \& Misuse, 1-7.

Keul, A., \& Eisenhauer, B. (2018). Making the high country: Cannabis tourism in Colorado USA. Annals of Leisure Research, 1-21. https://doi.org/10.1080/11745398.2018.1435291

Krauss, M., Sowles, S., Stelzer-Monahan, H., Bierut, T., \& Cavazos-Rehg, P. (2017). "It Takes Longer, but When It Hits You It Hits You!": Videos About Marijuana Edibles on $\begin{array}{lllll}\text { YouTube. Substance } \quad \text { Use } \quad \text { 7 } & \text { Misuse, } & \text { 52(6), }\end{array}$ https://doi.org/10.1080/10826084.2016.1253749

Labrecque, J., Dufour, J. C., \& Charlebois, S. (2011). Perceived health value of ready meals and side dishes: regional and gender differences. Young Consumers, 12(3), 204-215. https://doi.org/10.1108/17473611111163269

Labrecque, J., Dulude, B., \& Charlebois, S. (2015). Sustainability and strategic advantages using supply chain-based determinants in pork production. British Food Journal, 117(11), 2630-2648. https://doi.org/10.1108/BFJ-02-2015-0068

Lamy, Daniulaityte, Sheth, Nahhas, Martins, Boyer, \& Carlson. (2016). Those edibles hit hard: Exploration of Twitter data on cannabis edibles in the U.S. Drug and Alcohol Dependence, 164, 64-70. https://doi.org/10.1016/j.drugalcdep.2016.04.029

Le Vallée, J. C., \& Charlebois, S. (2015). Benchmarking global food safety performances: the era of risk intelligence. Journal of food protection, 78(10), 1896-1913. https://doi.org/10.4315/0362-028X.JFP-15-044

Lexaria Gets Notice of Its First Patent to be Granted in Australia for Cannabinoid Infused Edibles. (2017, March 03). Health \& Beauty Close - Up; Jacksonville.

Lexaria Applauds Canada's Proposed Cannabis Legislation. (2017, April 21). Health \& Beauty Close - Up; Jacksonville.

Lexaria Corporate Facts (2018). Internal corporate documents.

Maccoun, \& Mello. (2015). Half-Baked - The Retail Promotion of Marijuana Edibles. The New England Journal of Medicine, 372(11), 989-991. https://doi.org/10.1056/NEJMp1416014

Malek, Shabnam. (2017). Trademarks and branding in the cannabis industry: Protecting IP in the shadow of the CSA. The SciTech Lawyer, 13(3), 12-13, 30.

Mold, A. (2017). Cannabis; Getting High: Marijuana Through the Ages. Cultural and Social History, 1-2.

Nasser, R., Cook, S., Bashutski, M., Hill, K., Norton, D., Coleman, J., ... \& Charlebois, S. (2011). Consumer perceptions of trans fats in 2009 show awareness of negative effects but limited concern regarding use in snack foods. Applied Physiology, Nutrition, and Metabolism, 36(4), 526-532. https://doi.org/10.1139/h11-045

Olive, D. (2018, January 06). Six potential game-changers for 2018. Toronto Star, p. B.4.

Rehm, J., Crépault, J., \& Fischer, B. (2016). The Devil Is in the Details! On Regulating Cannabis Use in Canada Based on Public Health Criteria. International Journal of Health Policy and Management, 6(3), 173-176. https://doi.org/10.15171/ijhpm.2016.114 


\section{Macrothink}

Richards, Smith, \& Moulin. (2017). Unintentional Cannabis Ingestion in Children: A Systematic Review. The Journal of Pediatrics, 190, 142-152. https://doi.org/10.1016/j.jpeds.2017.07.005

Szaflarski, \& Sirven. (2017). Social factors in marijuana use for medical and recreational purposes. Epilepsy \& Behavior, 70, 280-287. https://doi.org/10.1016/j.yebeh.2016.11.011

Sobesky, \& Gorgens. (2016). Cannabis and adolescents: Exploring the substance misuse treatment provider experience in a climate of legalization. International Journal of Drug Policy, 33, 66-74. https://doi.org/10.1016/j.drugpo.2016.02.008

Spackman, E., Haines-Saah, R., Danthurebandara, V., Dowsett, L., Noseworthy, T., \& Clement, F. (2017). Marijuana Use and Perceptions of Risk and Harm: A Survey among Canadians in 2016. Healthcare Policy, 13(1), 17-27. https://doi.org/10.12927/hcpol.2017.25194

Vo, Horng, Li, Ho, Wu, Lynch, \& Smollin. (2018). Cannabis Intoxication Case Series: The Dangers of Edibles Containing Tetrahydrocannabinol. Annals of Emergency Medicine, 71(3), 306-313. https://doi.org/10.1016/j.annemergmed.2017.09.008

Vogel, L. (2017). Health on the hill: Six health bills to watch. Canadian Medical Association Journal, 189(44), E1373-E1374. https://doi.org/10.1503/cmaj.109-5514

Wang, X., Mackowsky, D., Searfoss, J., \& Telepchak, M. (2016). Determination of Cannabinoid Content and Pesticide Residues in Cannabis Edibles and Beverages. LC GC North America, 20-27.

Werb, Nosyk, Kerr, Fischer, Montaner, \& Wood. (2012). Estimating the economic value of British Columbia's domestic cannabis market: Implications for provincial cannabis policy. International Journal of Drug Policy, 23(6), 436-441. https://doi.org/10.1016/j.drugpo.2012.05.003

Yin, R. K. (1994). Discovering the future of the case study. Method in evaluation research. Evaluation practice, 15(3), 283-290. https://doi.org/10.1016/0886-1633(94)90023-X

\section{Copyright Disclaimer}

Copyright for this article is retained by the author(s), with first publication rights granted to the journal.

This is an open-access article distributed under the terms and conditions of the Creative Commons Attribution license (http://creativecommons.org/licenses/by/3.0/). 